\title{
De ramp tussen werkelijkheid en
}

\section{constructie}

\section{Huub Wijfjes}

Zoveel is zeker: zolang er mensen zijn, overkomen hen rampen. Maar wat is een ramp precies? Sommige staan zo buiten kijf dat een simpel woord genoeg is om ze aan te duiden: de watersnoodramp, de Bijlmerramp, de vuurwerkramp, de Herculesramp, de wTC-ramp. Maar soms is het ook minder voor de hand liggend om over een ramp te spreken. Niemand spreekt van een ramp in verband met de meer dan duizend doden die elk jaar in het wegverkeer vallen. Een paar krantenberichtjes volstaan. De vele duizenden doden die jaarlijks vallen als gevolg van roken en drinken, halen de krant al niet eens meer.

Dat kan men selectieve waarneming noemen, maar interessanter is de vraag onder welke omstandigheden, door wie en in welke vorm een catastrofe dan als ramp wordt gedefinieerd. Een blik in de geschiedenis leert dat rampen al vanaf het moment dat ze uitvoerig worden beschreven door pers en andere media (en dat is ongeveer sinds het begin van de negentiende eeuw) grofweg hetzelfde patroon te zien geven. ${ }^{1}$ In het kort komt dat neer op een opeenvolging van de volgende onderdelen. Het begint met het signaleren van onaangekondigde gebeurtenissen waarbij groepen mensen, bijeen op een bepaalde plaats, zo zwaar getroffen worden door zwaar natuurgeweld, verkeersgeweld of menselijke geweld dat vele doden vallen en materiële schade ontstaat. Na het opnemen van de eerste schade komt de nadruk te liggen op de hulpverlening, het beperken van verdere schade en het opruimen van de rommel. Pas geleidelijk daarna komen de ervaringen van slachtoffers aan de orde, inclusief de manier waarop de doden zijn begraven en de overlevenden zijn opgevangen en van hulp en troost zijn voorzien. Vervolgens wordt de schade meer gedetailleerd opgenomen, waarbij de aandacht zich concentreert op autoriteiten die iets kunnen of moeten doen. Die aandacht is enerzijds toekomstgericht op maatregelen die herhaling kunnen voorkomen en anderzijds verledengericht op het afrekenen met gemaakte fouten. Bij dat laatste komt ook de relatie tussen de burger en zijn vermogen om het eigen lot te bepalen aan de orde. Vervolgens is er de reactie van de 
samenleving die tot uiting komt in een combinatie van hulpvaardigheid en voyeurisme. Steunacties en ramptoerisme gaan al bij negentiende-eeuwse rampen samen en dat doen ze nog.

Het patroon verloopt steeds hetzelfde, maar er zitten nogal grote verschillen in de mate en vorm waarin onderdelen van dat patroon aandacht kriigen in media, politiek en samenleving. Drie in de tijd gespreide, maar in schadeomvang vergelijkbare voorbeelden kunnen dat kort aantonen. Toen op 7 oktober 1946 een militair vliegtuig neerstortte op de gymzaal van de christelijke HBS in Apeldoorn waardoor 27 leerlingen werden overdekt met brandwonden en 22 de dood vonden, werd weliswaar gesproken over 'een tragedie' die door voornamelijk lokale kranten werd beschreven, maar de doden werden in alle stilte begraven en de lokale en landelijke politiek en media gingen weer snel over tot de orde van de dag. De brand die op 9 mei 1977 het leven kostte aan 33 gasten van het Amsterdamse hotel Polen en die 46 gasten verwondde, werd door de media de dag na de brand weliswaar groot en dramatisch gebracht, maar toch als niet meer dan 'een forse, uitslaande brand met dodelijke slachtoffers'. Het woord 'ramp' viel in dat verband niet en al na enkele dagen was het onderwerp uit de kranten verdwenen. De cafébrand die in de nieuwjaarsnacht van 2001 in Volendam dertien dode en negentig gewonde tieners eiste, werd echter in ongekende mate en vrijwel onmiddellijk tot een ramp verklaard. Nog maanden woekerde deze 'ramp' door in media en politiek, een spoor achterlatend van stille tochten, stoepen met brandende waxinelichtjes, blijken van medeleven uit het hele land, onderzoeksrapporten en politieke slachtoffers.

Datzelfde was al te zien geweest bij de Bijlmerramp, de Herculesramp en de vuurwerkramp, allemaal gebeurtenissen van na 1990. Dat roept de vraag op of er in deze periode wellicht sprake is van een 'rampinflatie', een dusdanig verlies aan rationeel-kritische distantie bij dramatische gebeurtenissen dat de rampen intenser en emotievoller lijken, langer lijken te duren en zwaardere politieke en maatschappelijke consequenties lijken te hebben. Meestal wordt ter verklaring van dit verschijnsel gewezen naar de media die een onstilbare honger zouden hebben naar grootse, emotionele en verbeeldbare gebeurtenissen. Dat is een verleidelijke gedachte, want de beeldmedia staan centraal in de cultuur van de jaren negentig. Men kan dan zelfs, indien men Jean Baudrillard heet en in postmoderne dimensies denkt, het verschijnsel ramp provocatief tot uitsluitend een media- of televisieconstructie verklaren. ${ }^{2}$ Van rampen, zo luidt dan de opvatting, zou alleen maar sprake zijn als media erover in bepaalde mate en vorm rapporteren. Want media bepalen steeds meer (misschien zelfs uitsluitend) hoe wij gebeurtenissen waarnemen en interpreteren. De individuele eigen ervaring, die bijvoorbeeld een verkeersslachtoffer doet spreken van een ramp als hij het heeft over zijn ongeluk, verliest haar kracht en wordt volledig in de schaduw gezet 
van media-ervaring. Slechts op grond van de ervaringen van mensen die rampzalige gebeurtenissen waarnamen en er over rapporteerden (journalisten doorgaans) kunnen mediarampen worden geconstrueerd. De wat cynische conclusie is dan dat hoe meer media aanwezig zijn, hoe omvangrijker en dramatischer de ramp zal worden geconstrueerd. Zijn ze totaal afwezig, ontbreekt het beeld en zijn er ook geen journalisten of andere mediamakers aanwezig, dan is er geen ramp.

Voor een dergelijke opvatting is veel te zeggen, maar er kleeft toch ook een aantal bezwaren aan. Zo wil nog wel eens worden weggecijferd dat een 'ramp' (je durft het woord nog nauwelijks te gebruiken) voor de direct betrokkenen wel degelijk een spijkerharde realiteit is, waarover de media terecht rapporteren. Een dode blijft een dode en een verminkte een verminkte, ook in een postmodern tijdvak. Tevens wordt nog wel eens vergeten dat media opereren binnen een politiek en cultureel patroon dat medebepalend is voor de wijze waarop tegen verschijnselen wordt aangekeken. Rampen zijn voor een groot deel cultureel bepaald; rampen moeten als het ware in het kader 'passen' van wat de maatschappij op dat moment als rampzalig definieert. Vervolgens geeft een maatschappelijke reactie op een ramp inzicht in de manier waarop een cultuur met zijn problemen omgaat. ${ }^{3}$ Zo werd de brand in Volendam een ramp omdat het een groep Nederlandse jongeren betrof die cultureel en emotioneel samenhing door hun leeftijd, hun traditionele banden in een katholiek vissersdorp en hun verlangen het nieuwjaarsfeest te vieren in trendy synthetische uitgaanskledij. Die 'warme' samenhang werd 'kil' verstoord door een met politiek-bureaucratische nonchalance omgeven gebeurtenis, waarbij de individuele roekeloosheid van een café-eigenaar een belangrijke rol speelde.

Al die factoren waren vrijwel identiek aanwezig toen een voor zijn moeder stuntende vliegtuigpiloot, niet tegengehouden door een slapende vliegverkeersleiding, in 1946 in Apeldoorn een groep christelijke jongens uit klas $2 \mathrm{c}$ in hun gympakjes trof. ${ }^{4}$ Paste de 'kille' verstoring van een 'warme' groep niet in de cultuur van 1946? Recent historisch onderzoek geeft daar veel aanwijzingen voor. Er is bijvoorbeeld omvangrijk onderzoek gedaan naar de opvang en begeleiding van slachtoffers van de Tweede Wereldoorlog, een tijdvak barstensvol met wat we tegenwoordig 'rampen' zouden noemen. Grote groepen werden slachtoffer van vervolging, moord, ontheemding, verwoesting, honger en marteling. Diepgaand onderzoek heeft nu uitgewezen dat de opvang van deze slachtoffers in ónze ogen overkomt als kil, afstandelijk en hardvochtig, maar dat het goed past in het patroon waarop in de naoorlogse jaren met problemen werd omgegaan. Er werd weliswaar gesproken van een grote 'tragedie' of 'catastrofe' die Nederland, in het bijzonder de Joden, had getroffen, maar de blik werd vervolgens massaal gericht op de toekomst om snel de hevige oorlogservaringen te kunnen ver- 
geten en om structuren te ontwerpen die herhaling van de catastrofes zouden kunnen voorkomen. Ook bestond er een, zelden direct uitgesproken, opvatting over de beperkte rol van de overheid in het lenigen van de nood van individuele burgers. Bij de media bestonden opvattingen die hen nu juist niet dreef in de richting van het verwoorden of verbeelden van individuele nood. Burgers zouden in die opvatting hun problemen voornamelijk zelf moeten zien op te lossen, bij voorkeur met steun van directe familie of de lokale gemeenschap en binnen rudimentaire kaders die de overheid aanreikte. De media kenden in deze jaren weinig behoefte om de verhalen van individuele slachtoffers van bijvoorbeeld de holocaust of het Duitse en Japanse kampsysteem breed uit te meten. Des te meer aandacht had men voor de officiële hulpverlening en alles wat daarmee samenhing.'

In dat licht moet de politieke en mediale constructie van de vliegramp in Apeldoorn gezien worden, maar bijvoorbeeld ook die van de watersnoodramp van I953. Dat was de grootste natuurramp die Nederland in de twintigste eeuw meemaakte (gemeten naar objectief vaststelbare gegevens zoals het aantal doden en gewonden en de hoogte van de materiële schade). Zoals ook zal blijken uit de artikelen in dit themanummer zag men in de ramp bovenal een noodlottige speling van de natuur, door sommigen vertaald als de straffende hand van God, door anderen gezien als een bevestiging van de nietigheid van de mens ten opzichte van de natuur. Geen enkel mens, zo luidde de algemene opvatting, was tegen dat toevallige natuurgeweld bestand en het enige dat zinvol leek was maatregelen te treffen om de gevolgen van dergelijk natuurgeweld in de toekomst te verkleinen. Deze toekomstgerichtheid leidde tot een zeer beperkte behoefte om in het verleden naar mogelijke menselijke oorzaken of schuldigen te zoeken. De media opereerden ook in dit cultureel patroon en dus stelden journalisten weinig tot geen vragen naar het verleden, de oorzaken of de verantwoordelijkheden. Ze benadrukten vrijwel allemaal de herö̈sche strijd van hulpverleners, autoriteiten en slachtoffers om de problemen die de ramp had veroorzaakt te overwinnen. ${ }^{6}$

De sterk veranderende cultuur blijkt uit de perceptie van meer recente rampen. De vuurwerkramp die de Enschedese wijk Roombeek in mei 2000 trof en 22 doden en 946 gewonden kostte, maakte juist een enorme behoefte los om af te rekenen met het verleden, vooral met mensen die zaken hadden nagelaten of fout gedaan. Niemand had het meer over God, de voorzienigheid, de natuur of het toeval; wel over een aantal, bij voorkeur met naam en toenaam aangeduide, verantwoordelijke personen die langdurig met vragen, beschuldigingen en aanklachten werden achtervolgd. Na de ramp openbaarde zich tevens een grote behoefte aan erkenning van allerlei kwesties en problemen, soms algemeen maatschappelijk, meestal particulier. De ramp veroorzaakte een vloed an mediaverhalen over veiligheidsbeleid, achterstandswijken, allochtonenproblematiek en zorgzame overheid. In een tijd 
vol met bedreigingen van de traditionele cultuur, geweld tegen individuen en falende politiek, kon de ramp uitgangspunt zijn van talloze nieuwsverhalen. Dat leidde tot een mediaconstructie vol openbaar verdriet en rouwritueel enerzijds en afrekening met falende autoriteiten anderzijds.

Deze zelfstandige mediadynamiek die de problemen en behoeften van een geïndividualiseerde cultuur voortdurend probeert te representeren in originele, emotioneel-menselijke verhalen die gerelateerd worden aan een falende politiek, roept vele vragen op. Wat is nu precies die rol van de media en in hoeverre zegt de media-aandacht nu werkelijk iets over rampen en rampperceptie? Het is onmiskenbaar dat de enorm gegroeide presentie van vooral de beeldmedia heeft geleid tot het sneller en heviger 'construeren' van rampen indien daarvan beelden beschikbaar zijn. De ramp die New York op II september 200 I trof heeft een diepte en reikwijdte gekregen mede dankzij de beschikbaarheid van een ongelofelijke hoeveelheid uitzendklaar televisiebeeld. Op wereldschaal konden beeldmedia daardoor een gemeenschappelijke ervaring van nabij crisisgevoel scheppen die ongekend was. De wTCramp was een meta-event, een gebeurtenis zo omvangrijk en zo mediageniek dat ze gemeenschappelijke ervaring op wereldschaal creëerde. De wTCramp is er een in het rijtje: de moord op Kennedy, de man op de maan, de val van de Muur en de dood van Diana.

Als de huidige media- en cultuurwetenschap het over dergelijke gebeurtenissen hebben, volstaan onderzoekers al lang niet meer met de registratie van blote feiten en rationele verbanden; het gaat hen dan om de symbolen en de waarden die rampen representeren en de gevoelens die ze oproepen. De instorting van de Twin Towers was niet alleen, concreet, een geplande aanslag van acht moslimfundamentalisten waarbij meer dan 2000 doden vielen, maar, meer symbolisch, 'een aantasting van de Amerikaanse droom en de liberale vrijheid'. Sommigen spraken over de ramp als het einde van 'New York's multicultural dream of living together in peace'. Anderen zagen in de ramp een bevestiging van 'Amerika's falen in de wereld' of het bewijs voor de kracht van het islamitisch fundamentalisme. En zo zijn er nog honderden andere interpretaties van hetzelfde verschijnsel, dat we simpel aanduiden als de wTC-ramp. Allerlei zaken die media rondom het oorspronkelijke feit rapporteerden, versterkten het gevoel dat de inzakkende torens geen gebeurtenis met een begin en een einde was, maar een symbool of 'icoon' voor een werkelijk keerpunt in de geschiedenis. De wereld stopte als het ware even, aarzelde en sloeg nieuwe wegen in. De financiële wereld en de bedrijvigheid raakten in paniek, politici reisden van hot naar her, televisieprogrammeringen werden aangepast, bevolkingsgroepen keken elkaar anders in de ogen, politieke verhoudingen veranderden, overal werden minuten stilte in acht genomen en het sportcircus leek zijn betekenis te verliezen.? 
Deze opmerkingen klinken aannemelijk dankzij de hoogdravendheid ervan. Ze lijken de media, vooral de televisie, tot het centrum van alle gebeurtenissen, van alle opinievorming en van alle ervaring te willen maken. Dat is een begrijpelijk standpunt in een wetenschapsgebied dat betekenissen deconstrueert en construeert vanuit persoonlijke ervaring die men relateert aan culturele context. Maar dergelijke standpunten zijn lang niet altijd houdbaar wanneer men meer concreet en systematisch analyseert wat er nu precies gebeurt bij een ramp. Vele studies van sociologen, (massa)psychologen, historici, politicologen en een enkele communicatiewetenschapper hebben concreet in kaart gebracht hoe rampen verlopen vanaf de feitelijke gebeurtenis tot aan de politieke en maatschappelijke afwikkeling en die leveren een heel ander beeld op, waarin media niet het centrum van betekenisgeving zijn, maar een van de vele schakels in een keten van participanten, betrokkenen en verantwoordelijken. ${ }^{8}$

Dit met nadruk geconstateerd hebbend, kunnen we er toch niet omheen dat inhoudsanalyse uitwijst dat de media-aandacht voor rampen in de loop van de twintigste eeuw sterk van karakter veranderd is. Het mediaveld is in een technologische stroomversnelling beland: er zijn meer media, die steeds vaker en in grotere hoeveelheden inhoud produceren. In verhevigde concurrentieverhoudingen spreken ze meer en grotere publieksgroepen in een steeds hoger tempo aan. Het volume van de media-aandacht voor een ramp zwelt in de loop der tijd sterk op, de aandacht houdt langer aan, met een grotere en meer gevarieerde inhoud en met een hogere behoefte aan invoelbaarheid. Binnen dat media-aanbod zijn twee grote perspectiefwisselingen aanwijsbaar die tussen de jaren zeventig en negentig geleidelijk hebben plaatsgevonden: de emancipatie van private emotie en de politisering van de schuldvraag. Aan de ene kant brengen media de emotie en de ervaring extreem nabij de individuele mediaconsument, aan de andere kant plaatsen ze zijn eventuele eigen verantwoordelijkheid juist op afstand. Om het in andere woorden te zeggen: de media gaan het belang van de individuele emotie voortdurend benadrukken door ruim baan te geven aan uiterst persoonlijke ervaringsverhalen met een hoge emotionele inhoud, maar de individuele verantwoordelijkheid wordt steeds meer verschoven naar onpersoonlijke velden zoals de politiek, het openbaar bestuur en maatschappelijke organisaties. Dat lijken twee tegengestelde trends die echter onder de noemer 'individualisering' kunnen worden samengebracht.

Media zijn hierdoor dominanter aanwezig bij de feitelijke ontwikkeling van de ramp en de nasleep. In het bijzonder in de beginfase, waarin de gebeurtenissen nog vers, talrijk en onoverzichtelijk zijn, kunnen de media een doorslaggevende rol spelen in het 'labelen' of identificeren van de situatie. In het verdere verloop van de opeenvolgende gebeurtenissen kunnen media dusdanig eenduidige accenten leggen, vragen stellen en nieuwsverha- 
len inkaderen dat de aard van de discussies en uiteindelijk ook de aard van de besluiten wordt beïnvloed. Het zogenaamde crisisonderzoek van sociologen en politicologen vat dit proces samen door te spreken van 'mediatisering van crises en rampen'.' In de communicatiewetenschap spreekt men liever van 'de eigen dynamiek van het mediagedrag'. Kortheidshalve zijn daarvoor de begrippen 'mediahype' en 'publiciteitsgolf geformuleerd. ${ }^{10}$

Maar wat al dat onderzoek ook uitwijst is dat mediatisering van crises niet de enige factor van betekenis is in de identificatie, de betekenisconstructie en het verloop van de afwikkeling van rampen. In dat verband vallen ook termen zoals individualisering van cultuur, juridisering van conflictoplossing, politisering van misstanden en emotionalisering van openbaar debat. Het zijn begrippen die aanduiden dat niet alleen media bepalend zijn, maar dat het uiteindelijk de politiek, het openbare bestuur en maatschappelijke organisaties zijn die op cruciale momenten cruciale beslissingen nemen. Wellicht onder druk van media-aandacht, maar toch ook reagerend op elkaar, binnen bepaalde machtsverhoudingen, vanuit de eigen opvattingen en rekening houdend met allerlei specifieke factoren die men nu eenmaal belangrijk vindt.

Dit themanummer verschijnt 50 jaar nadat de watersnood op I februari 1953 een einde maakte aan 1835 levens in Zeeland, West-Brabant en ZuidHolland. Reflectie op de manier waarop met dergelijke en latere rampen is omgegaan, kan geen kwaad. Sterker nog, het kan veel verhelderen over de plaats die rampen in onze huidige tijd hebben en hoe media daarin functioneren. Maar de actuele thematiek staat niet voorop en heeft niet alles bepaald, zoals het hoort in een historisch tijdschrift. De redactie van TMG heeft getracht om het concrete historisch onderzoek naar de mediaconstructie van rampen nader te belichten. Historica Margrith Wilke laat aan de hand van visuele voorbeelden zien hoe de persfotografie er in de loop van de twintigste eeuw steeds meer in slaagt het persoonlijke en het esthetische van de rampervaring uit te lichten. Twee studies van Groningse studenten zijn opgenomen over de watersnoodramp van 1953. Kirsten Noyons toont in een gedetailleerde reconstructie van het radiogeluid aan dat het populaire beeld van een suffe en brave journalistiek niet altijd goed past bij de intense manier waarop radiojournalisten in de eerste dagen na de ramp de gevoelens van verslagenheid en verdriet over de schade proberen te combineren met dankbaarheid en optimisme over de hulpverlening. Eva Hulscher wijst ons er op dat dagbladjournalisten niet los opereerden van de politieke context van hun tijd. Hun verzwijgen van de schuldvraag ten aanzien van de watersnoodramp past in het verzwijgen van dezelfde vraag in de landelijke en regionale politiek. 
Peter Vasterman en Joris IJzermans gaan in op de vraag hoe de autonome mediadynamiek daadwerkelijk leidt tot belangrijke maatschappelijke effecten. Op grond van een inhoudsanalyse en medische gegevens stellen ze vast dat de veelgehoorde bewering over een mogelijke samenhang tussen media-aandacht en het ontstaan van gezondheidsklachten na de Bijlmerramp aannemelijk is. Historicus en journalist Joost Lammers laat dezelfde vervlechting van politiek en journalistiek zien bij de rampen van Enschede en Volendam. Zijn artikel toont aan dat het NOS-JOURNAAL bij deze rampen in een eigen tempo en met eigen opvattingen over schuld en boete opereerde. Het kostte de Volendamse burgemeester de kop, maar de burgemeester van Enschede werd een mediaheld. Tot slot gunt Ruth Oldenziel, die als 'Amerika-deskundige' talloze malen in de media verschijnt, ons een blik in de werkelijkheid en schijnwerkelijkheid van met name de Amerikaanse media na de wTC-ramp. Haar essay toont aan dat de verpersoonlijking van de ervaring niet alleen in media, maar ook in het wetenschappelijke discours een functie heeft.

\section{Noten}

I Dit overzicht is gebaseerd op verschillende studies van rampen tussen 1868 en $200 \mathrm{in}$ : H. Wijfjes en M. Broersma (red.), Stop de persen! Journalisten verslaan rampen en ongelukken, 1868 -2000, papers Onderzoekscollege Rijksuniversiteit Groningen, afdeling Journalistiek 200I.

2 J. Baudrillard, The Gulf War did not take place, Sydney 1995.

3 Voor een algemeen overzicht zie: J.E. Ellemers, 'Rampen in Nederland', in: Sociologische Gids 48, nr. 3, 200I, pp. 231-252.

4 Informatie over deze ramp op: www.zero-meridean.com. Vgl. de ervaringsverhalen in: 7-10-1946 Waarom? uitgave Gemeentearchief Apeldoorn 1996.

5 M. Bossenbroek, De meelstreep. Terugkeer en opvang na de Tweede Wereldoorlog, Amsterdam 2001.

6 J.E. Ellemers, De februari-ramp. Sociologie van een samenleving in nood, Assen 1956; K. Slager, De ramp, Goes 1992.

7 E. Casey (ed.), og/II 8:48 am. Documenting America's Greatest Tragedy, e-book op Booksurge.com, vanaf oktober 2001 .

8 In Nederland is met name te wijzen op het onderzoek van het Crisis Onderzoek Team (сот), dat sinds de jaren zeventig vele publicaties heeft opgeleverd. Zie daarvoor: www.cot.nl. Vgl. de bijdragen in: J. Evers en H. Kleijer (red.), Rampenonderzoek, Amsterdam 2002.

9 Een samenvatting van de media-inzichten van het сот in: Crisis in het nieuws. Samenspel en tegenspel tussen overheid en media, Alphen aan den Rijn 1997.

Io Zie daarvoor uitvoerig: P. Vasterman, Mediahype: nieuws maken door de opwinding te verslaan, Utrecht 1999; Jaap van Ginneken, Brein-bevingen. Snelle omslagen in opinie en communicatie, Amsterdam 1999. 